\title{
SCIDoc

\section{Intra Abdominal Mass in Female Young Patient. The Challenge}

\author{
Nodar $\mathrm{SR}^{1 *}$, Yllán $\mathrm{VG}^{2}$, Solis $\mathrm{O}^{3}$, Boccara $\mathrm{G}^{3}$ \\ ${ }^{1}$ Pathologist and President of Foundation for Sciences and Research, Florida, USA. \\ ${ }^{2}$ Pathologist at Enrique Garcés Hospital, Av Enrique Garcés, Quito, Ecuador. \\ ${ }^{3}$ Foundation for Sciences and Research, Miami, Florida, USA.
}

\section{Abstract}

The abdominal region of the body is extremely complex because of the organs and systems it contains all of them generating abdominal masses, the discovery of which often poses significant diagnostic difficulties. A previously healthy, 21-yearold woman presented to the hospital with a severe abdominal pain and an abdominal mass, approximately $10 \mathrm{~cm}$ in size, raising a strong suspicion of a malignant tumor in the upper abdomen. She had history of abdominal cesarean. The patient elected to undergo exploratory surgery.

Keywords: Abdominal Mass; Textiloma; Medical Negligence; Medicolegal Aspect.

\section{Introduction}

The abdominal region of the body is extremely complex because of the organs and systems it contains such as the urogenital system, important blood and lymphatic vessels, the gastrointestinal tract, and nerves and parts of the musculoskeletal system, all of them housing or generating masses during current diseases, congenital alterations, inflammatory illness and tumors, and in paraphysiologic conditions [1-4].

Gynecological diseases are the main cause of female masses. However, a solitary mass discovered by ultrasonography in a young woman can also be due to extra gynecological causes among which are, less frequently, ascites, peritoneal pseudomixoma, mesenteric panniculitis and intraperitoneal foreign bodies [1].

Gray scale sonographic features of abdominal masses can be used to separate them into conventional categories (cystic, complex, solid), and to subcategorize into a useful differential diagnosis based on size, location, internal consistency, and definition of borders although these features are specific in only some types of masses [5-10].

In patients who undergo abdominal surgery and in patients with radioactive intraperitoneal treatment strong adherences originate, causing intraperitoneal fluid flow alterations provoking bags of peritoneal effusion simulating intraperitoneal masses. In cases of pseudomixoma, typical appearance is a liquid mass localized among the intestinal loops, sometimes with septa or solid buttons inside. The mass in mesenteric panniculitis is homogeneous and circumscribed by a peripheral pseudocapsule well delimited $[1,5-10]$.

Concerning to the intraperitoneal foreign bodies they are a consequence of surgical malpractice consisting in a non-biodegradable foreign body plus the surrounding reactive tissue [11-13].

\section{Presentation of the Case}

A 21 years old female was attended in Emergency room because a severe abdominal pain. On physical examination abdomen was flat, soft and depressible, painful on bilateral iliac zones and in hypogastric region where it was palpated a large, hard and immovable tumor. She had a previous history of cesarean three years before. No other previous remarkable health history.

On echography, it was reported level free homogeneous liquid pouch of Douglas and periadnexal, and besides it, a mass of liquid content with an echogenic center (Figure 1). Shape, size and echogenicity of adnexal structures were normal. In addition, a Simple and Contrasted abdominal CT was performed, showing the presence of a heterogeneous mass, $10.2 \mathrm{x} 4.9 \mathrm{~cm}$ in size, proba-

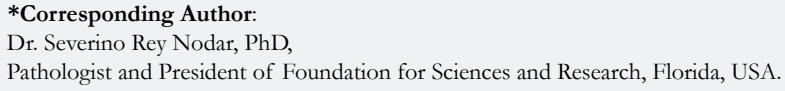

Copyright: Nodar SR ${ }^{\circ}$ 2017. This is an open-access article distributed under the terms of the Creative Commons Attribution License, which permits unrestricted use, distribution and reproduction in any medium, provided the original author and source are credited. 
ble intestinal origin suggesting ruling out a foreign body (bezoar), located in umbilical region, with distended bowel loops, thickened walls, mottled air inside, and with peripheral capture of the contrast with no homogeneous appearance in the central region. It was also reported the presence of free fluid in perihepatic region, right hepatorenal space, and bilateral parieto-colic and perivesical spaces.

The patient underwent a laparotomy. Although the exact diagnosis was uncertain at that time, there was a strong suspicion of a malignant tumor. It was performed a meticulous dissection of adhesions of peritoneum, omentum, bladder dome and small intestine. The surgical specimen was send to pathology.

Gross examination of the surgical piece described it as rounded, firm, yellowish, $10 \mathrm{~cm}$ larger diameter, with few amounts of mesenteric fat attached on its surface. The cut surface showed a thick fibrous wall cavity with large amount of friable, crumbly, hemorrhagic content and textile fiber material inside (Figures 2-4). On histological examination necro hemorrhagic content, laden macrophages with abundant inorganic material identified as textile fiber, and chronic granulomatous inflammatory reaction with moderate amount of foreign body giant cells was described. Also, extensive fibrosis and areas of hemorrhage. Diagnosis of textiloma was concluded.

The patient had a favorable clinical course and was discharged within a few days after surgery.

\section{Discussion}

Infrequently reported by the legal and medical implications it en- tails and because its possibility of causing serious complications, most often underestimated, Textiloma, Gasoma and/or Gossypiboma, was first reported by Wilson C.P., in 1884, as foreign bodies left in the abdomen after laparotomy [12]. It consists of a mass within the body that involves forgotten surgical material and its corresponding foreign body tissue reaction. Its name derived from Latin (gossi-pium/cotton), and Kiswahili (boma) that means "place of concealment", conceal, hide, site where it is hidden something and/or site where it is concealed something, place of confinement $[11,13,14]$.

Textile materials are the most commonly forgotten [15-17], but, also, other surgical materials such as artery forceps, pieces of broken instruments or irrigation sets, scissors, needles and rubber materials $[16,18,19]$.

The case we are reporting is important to review current aspects concerning to the retained postoperative textile foreign body, which is difficult to recognize in view of it can simulate hematoma, granulomatous process, abscess formation, fecalomas, cystic masses or a malignant neoplasm, as it happened in this patient.

The incidence of Gossypiboma is unknown (approximately 1:100-3000 in all surgical events and 1:1000-1500 in abdominal surgeries), and its clinical presentation very dissimilar. It can present with pain and abdominal mass, adhesions, abscess, granuloma, intestinal obstruction [20], drilling intestinal fistula, extrusion or bleeding, fatigue, weakness, weight loss [21-24] and can be diagnosed long time after surgery, even 30 years, especially when the surgical abandoned material remains sterile $[13,14,25,26]$. Sometimes it is incidentally detected through radiology made by other causes or during surgery performed for other reasons [26], including suspected malignancy [27].

Figure 1. On echography, It was Reported a Mass of Liquid Content with an Echogenic Center.

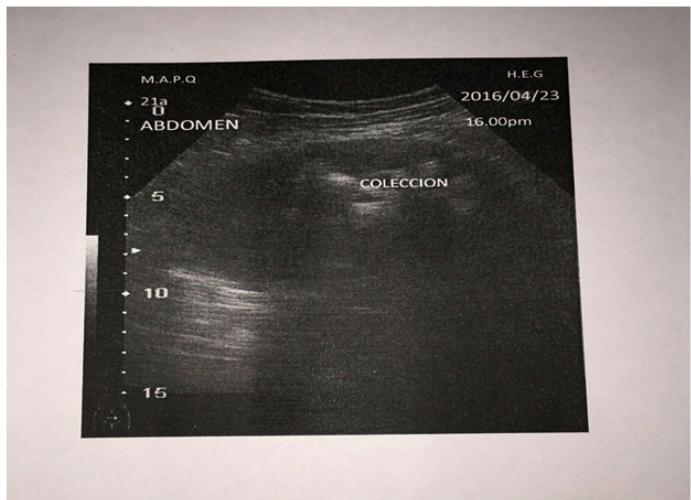

Figure 2. A rounded, firm, yellowish, $10 \mathrm{~cm}$ larger diameter mass, with few amounts of mesenteric fat attached on its surface.

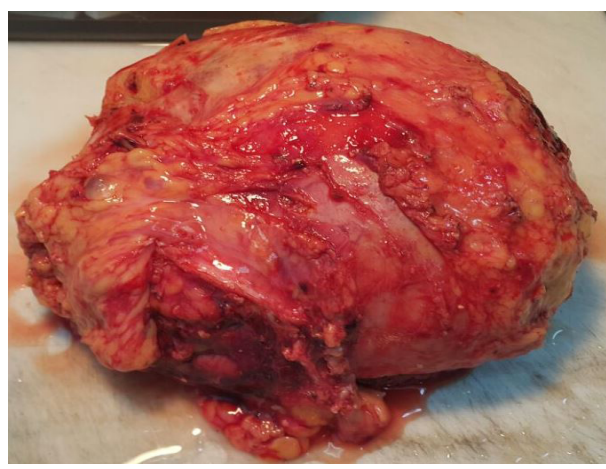


Figure 3. The cut surface shows a thick fibrous wall cavity with large amount of friable, crumbly, hemorrhagic content.

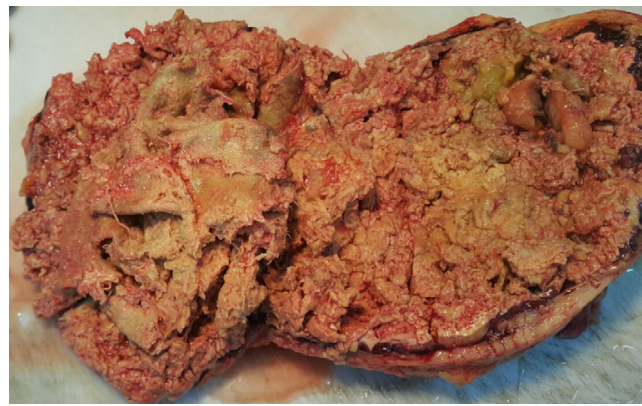

Figure 4. The cavity with textile fiber material inside.

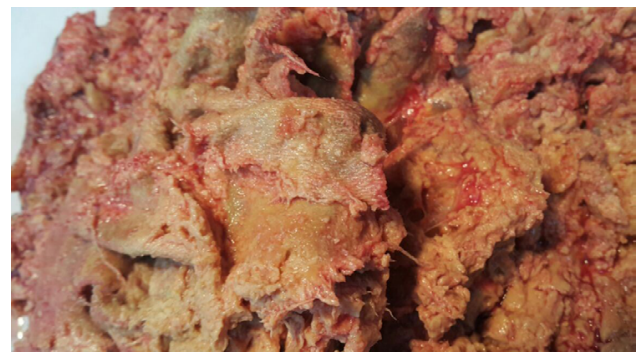

The emergency surgeries, changes in the type of planned surgery, extensive surgical procedures, are among the factors cited for such eventuality. In addition, changes in nursing staff during surgery, the presence of several surgical teams, disorganization, hurried sponge count, unstable patient condition, patients with high body mass index, and human mistake, inexperienced staff, and inadequate staff numbers $[15,20]$.

On the other hand, these events have been reported in abdominal, thoracic, cardiovascular, breast, orthopedic and neurological surgeries [24, 28-30].

According to the risk factors for retained foreign bodies (RFBs) published by the New England Journal of Medicine [20], in this case we can identify that count of gauzes was clearly not sufficient. Besides it, to have no policy regarding radiography, and probable malpractice in surgery, and deficient safety culture and quality management in the operating room.

The simply counting of the gauzes once completed the surgery does not guarantee that has not been forgotten one of these in the procedure. Their removal should be careful by keeping an exhaustive count during the preoperative, intraoperative and postoperative moments, and a complete exploration by quadrants of the entire cavity by the surgeon and his team before closure.

Conforming to the WHO recommendations, two similar persons should always do this count separately in a consistent sequence, and should note their names in the count sheet or nursing record in addition with a methodical exploration of surgical wound by the operating surgeon [30].

These precautions decrease the likelihood of leaving surgical materials especially in cases the sponges do not have any radiological marker on themselves, as in the case we present, being difficult the diagnosis by using radiological screening.
If there is any doubt in the counts, immediate intraoperative Xrays should be indicated to detect materials such as gauze sponges. Technologies for detection include two-dimensional bar code, radiofrequency detector, and radiofrequency identification. The two-dimensional bar code system incorporates a specific code to each sponge, which prevents double count. The radiofrequency detector identifies sponges by radiofrequency beacons, which cause base station to produce a beep when they remain underneath. The later technique, radiofrequency identification, is a modification of radiofrequency detector where a tag is attached to each sponge. The surgical sponge is incorporated with radiopaque markers (density equivalent to $0.1 \mathrm{~g} / \mathrm{cm}$ sup $\mathrm{BaSO}_{4}$ ) in between layers or strips or outside fibers [30].

Therefore, once collected an appropriated clinical history of an abdominal mass, the best examination is the ultrasonography. The echography describes it as a mass of liquid content, with intralesional linear and hyperechoic wavy structures, an echogenic lesion in its center and a rear sonic shadow not associated with gas and/or calcifications. Occasionally, it can adopt a fully anechoic pattern image, with liquid content, sometimes with irregular internal echoes of varied sizes or with hypo echogenic patterns or complex mass patterns $[15,20,31]$.

In some cases, is difficult to evaluate the nature of the lesion, then a CT or MRI scan is required. On CT scan, forgotten surgical material is well defined, and a dense wall (that may or may not be present on post contrast IV enhancement) accompanies it. The center of the lesion has an appearance of twirl, swirl ("whirl-like" pattern) due to gas trapped within the network of fibers of the textile material. It is also possible to demonstrate fluid levels within or gas, indicating the formation of an abscess that determines the differential diagnosis with a hematoma. In long-standing cases, surgical forgotten material can calcify $[15,20,32]$.

Contrast-enhanced CT scan usually demonstrates a solid space- 
occupying lesion, with soft tissue density, with reinforcement in the wall with a hyperdense area inside, with or without air bubbles, identifying, in addition, fistulous trajectories originating in the cavity of intralesional abscesses that are discovered through gastrointestinal contrast studies $[15,20,32]$.

Textiloma is a rare condition that usually goes unnoticed. It diagnosis is a challenge for surgeons because of its nonspecific clinical manifestations, varied imagenological appearance, and because it is uncommon to consider it.

In this patient the suggestive clinical manifestations of abdominal pain, palpable tumor and age, led surgeons to the diagnosis of probable intra-abdominal neoplastic processes. However, when the Simple and Contrasted abdominal CT was performed to the patient it showed a heterogeneous mass, probable intestinal origin, and suggest ruling out a foreign body, but it was no considering the previous history of abdominal surgery and consequently the possibility of a foreign body was not considered among the probable differential diagnoses.

It is exceptional to forget a gauze in a cavity in a surgery, but even though according to the medical reports the mortality associated varies from $0 \%$ to $35 \%[26,33-35]$, its consequences are very important.

It can be free in the abdominal cavity or it can migrate from this to some intra-abdominal hollow viscera in an attempt by the body to get rid of it. When entering the intestine through the ileocecal valve, the body may expel it in the stool [36]. It can also migrate to the chest by trans diaphragmatic via; and to the stomach, small intestine and colon, causing intestinal obstruction syndrome; to the bile duct causing obstructive jaundice, and to the bladder with partial transurethral externalization [36-44].

On the other hand, it may cause extrinsic compression by the mass effect generated by being close to a hollow organ. In these cases, the diagnosis is very difficult through images due to the close anatomical relationship with the abdominal organs $[45,46]$.

Once it is diagnosed the presence of textiloma, it is recommended its removal due to the potential and unpredictable medical and/or legal complications, such as reoperation scheduled or emergency surgery, deeper and expensive studies to rule out certain pathologies, and death as a direct result of complication of textiloma itself, or its treatment $[26,29,32]$.

Although it has been found without any apparent medical consequences, and even in patients who have refused treatment, they have been imposed lawsuits against surgical teams [27]. Patient may prosecute the responsible surgeon, and the surgeon will face humiliation, shame, charges of negligence and loss of reputation.

\section{Conclusions}

The surgical material forgotten in the abdominal cavity causes very varied clinical manifestations, and it is potentially harmful from the point of legal and medically aspects.

Considering every single surgical operation is a risk, surgeon should always remain vigilant and precautious as the diagnosis of
Gossypiboma proves his neglect. Its medicolegal consequences include humiliation, monetary compensation and sentence on the part of the surgeon, and increased morbidity, mortality and economic loss on the part of the patient. Therefore, prevention always remains the better alternative.

Nevertheless, despite the precautions taken in all surgeries this complication continues to observe so it should always be considered as a differential diagnosis of intra-abdominal mass when there is surgical previous history.

\section{References}

[1]. Francesco Alessandrino, Carolina Dellafiore, Esmeralda Eshja, Francesco Alfano, Giorgia Ricci, et al., (2013) Differential Diagnosis for Female Pelvic Masses. Medical Imaging in Clinical Practice. InTech, DOI: 10.5772/53139.

[2]. Sostres JN (1961) original: Exploration of intra-abdominal tumors in women. Annals of women. 41(166): 255-282.

[3]. García MG, Gil MF, Cano AB, López SA (2008) Diagnóstico de las masas abdominales de origen intestinal y/o mesentérica. Medicine-Programa de Formación Médica Continuada Acreditado. 10(4): 269-271.

[4]. Duque CDV, Corrales CB, Toncel SR, Montealegre DQ (2016) Anatomia Y Patologia A Del Peritoneo en Escanografia: ensayo ilustrado.

[5]. Lovesio C (2002) Sindrome compartimental abdominal. Rev Med Rosario. 68: $97-100$

[6]. Suárez-Torres I, Reyna-Villasmil E (2017) Pseudomixoma peritoneal. Revista Peruana de Ginecología y Obstetricia. 63(1): 97-101.

[7]. Donald I, Macvicar J, Brown TG (1958) Investigation of abdominal masses by pulsed ultrasound. Lancet, 271(7032): 1188-1195.

[8]. Lawson TL, Albarelli JN (1977) Diagnosis of gynecologic pelvic masses by gray scale ultrasonography: analysis of specificity and accuracy. AJR Am J Roentgenol. 128(6): 1003-1006.

[9]. Rosón N, Garriga V, Cuadrado M, Pruna X, Carbó S, et al., (2006) Sonographic findings of mesenteric panniculitis: correlation with CT and literature review. J Clin Ultrasound, 34(4): 169-176.

[10]. van Breda Vriesman AC, Schuttevaer HM, Coerkamp EG, Puylaert JBCM (2004) Mesenteric panniculitis: US and CT features. Eur radiol. 14(12): 2242-2248.

[11]. Hunter TB, Taljanovic MS (2005) Medical devices of the abdomen and pelvis. Radiographics. 25(2): 503-23.

[12]. Rehman A, Baloch NUA, Awais M (2014) Gossypiboma diagnosed fifteen years after a cesarean section: A case report. Qatar Medical J. 2014(2): 6569. http://doi.org/10.5339/qmj.2014.12

[13]. Kokubo T, Itai Y, Ohtomo K (1987) Retained surgical sponges: CT and US appearance. Radiology. 165(2): 415-18.

[14]. Sarda AK, Pandey D, Neogi S, Dhir U (2007) PO complications due to a retained surgical sponge. Singapore Med J. 48(6): e160-e164.

[15]. Arpit N, Abhijit A, Ranjeet S, Bhatgadde VL (2002) Gauze pad in the abdomen: Can you give the diagnosis without knowing the history? J Radiol. 10: $132-136$.

[16]. Kataria SP, Garg M, Marwah S, Sethi D (2012) Acute abdomen by gossypiboma. Ann Trop Med Publ Health. 5(5): 511-513.

[17]. Sun H, Chen S, Kuo C, Wang S, Kao Y (2007) Gossypiboma: retained surgical sponge. J Chin Med Assoc. 70(11): 511---513.

[18]. Gibbs VC, Coakley FD, Relines HD (2011) Preventable errors in the operating room: retained foreign body in surgery. Curr Prob Surg. 44(5): 261--337 .

[19]. Karahasanoglu T, Unal E, Memisoglu K, Sahinler I, Atkover G (2004) Laparoscopic removal of a retained surgical instrument. J Laparaendosc Adv Surg Tech A. 14(4): 241-243.

[20]. Gawande AA, Studdert DM, Orav EJ, Brennan TA, Zinner MJ (2003) Risk factors for retained instruments and sponges after surgery. NEJM. 348(3): 229-35.

[21]. O'Connor AR, Coakley FV, Meng MV, Eberhardt S (2003) Imaging of retained surgical sponges in the abdomen and pelvis. AJR. 180(2): 481-9.

[22]. Zbar AP, Agrawal A, Saeed IT, Utidjian MR (1998) Gossypiboma revisited: A case report and review of the literature. J R Coll Surg Edinb. 43(6): 417418.

[23]. Pérez GR, Rodríguez GH, Hernández BS, Zárate SA (1998) Textilomas that resemble abdominal tumor pathology. Description of six patients. Cir Gen. 20: 263-267.

[24]. Cruz-Fierro CM (1999) Abdominal textiloma. Gac Med Mex. 135(6): 657658.q 
[25]. Le Néel JC, De Cussac JB, Dupas B, Letessier E, Borde L, et al., (1994) Textiloma. Apropos of 25 cases and review of the literatura. Chirurgie Memoires de L'Academie de Chirurgie. 120(5): 272-6; 276-7.

[26]. Rajput A, Loud PA, Gibbs JF, Kraybill WG (2003) Diagnostic challenges in patients with tumors: Case 1. Gossypiboma (foreign body) manifesting 30 years after laparotomy. J Clin Oncol. 21(19): 3700-3701

[27]. Kaiser CW, Friedman S, Spurling KP, Slowick T, Kaiser HA (1996) The retained surgical sponge. Ann Surg. 224(1): 79-84.

[28]. Motta Ramírez GA, González Burgos O, Castillo Lima JA, Villalobos García E (2007) Material quirúrgico olvidado: Gossypiboma, textiloma, gasoma. Anales de Radiología México. 4: 285-296.

[29]. Gencosmanoglu R, Inceoglu R (2003) An unusual cause of small bowel obstruction: Gossypiboma. Case report. BMC Surg. 8(3): 6.

[30]. Biswas RS, Ganguly S, Saha ML, Saha S, Mukherjee S, et al., (2012) Gossypiboma and Surgeon- Current Medicolegal Aspect - A Review. Indian J Surgery. 74(4): 318-322. http://doi.org/10.1007/s12262-012-0446-3

[31]. Akhaddar A, Boulahroud O, Naama O, Al-bouzidi A, Boucetta M (2012) Paraspinal Textiloma After Posterior Lumbar Surgery: A Wolf in Sheep's Clothing. World Neurosurg. 77( 2): 375-380.

[32]. Ariz C, Horton KM, Fishman EK (2004) 3D CT evaluation of retained foreign bodies. Emerg Radiol. 11(2): 95-9.

[33]. Heffernan JP, Heidenberg HB, Irby PB, Moul JW (1997) Gossypiboma (retained surgical sponge) and recurrent bladder neck contracture after radical retropubic prostatectomy and bilateral pelvic lymph node dissection. J Urol. 157(4): 1356-1357.

[34]. Contreras-Ruiz VR (2007) En el olvido: Textiloma. An Med (Mex). 52(1): 37-41.

[35]. Rodríguez G, Ruso L, Bruno G, Balboa O (1997) Corpus alienum intraabdominal. Cir Uruguay. 67(2): 80-83.

[36]. Gibbs VC, Auerbach AD (2016) The retained surgical sponge. Evidence Re-
port/Technology Assessment No. 43, Making Health Care Safer: A Critical Analysis of Patient Safety Practices, AHRQ Publication No. 01-E058).

[37]. Dhillon JS, Park A (2002) Transmural migration of a retained laparotomy sponge. Am Surg. 68(7): 603-5.

[38]. Kabiri H, Caidi M, Benamor J, el Maslout A, Benosman A (2001) Intrathoracic textiloma caused by transdiaphragmatic migration after biliary surgery. Report of a case. Rev Pneumol Clin. 57(5): 362-5.

[39]. Lone GN, Bhat AH, Tak MY, Garcoo SA (2005) Transdiaphragmatic migration of forgotten gauze sponge: an unreported entity of lung abscess. Eur J Cardiothorac Surg. 28(2): 355-7.

[40]. Esposito S, Ragozzino A, Rossi G, Pinto A, Martino A (1994) Spontaneous migration of a surgical sponge in the small intestine. Apropos of a case studied with conventional radiology and CT. Radiol Med. 88(1-2): 139-41.

[41]. Yeung KW, Chang MS, Huang JF (2004) Imaging of transmural migration of a retained surgical sponge: a case report. Kaohsiung J Med Sci. 20(11): 567-71.

[42]. Godara R, Marwah S, Karwasra R, Goel R, Sen J,et al., (2006) Spontaneous transmural migration of surgical sponges. Assian J Surg. 29(1): 44-5.

[43]. Uzcategui E, González G (2009) Granuloma a cuerpo extrańo, simulando una enfermedad maligna del tracto biliar. Gastroenterol Hepatol. 32(1): $32-5$.

[44]. Cimsit B, Keskin M, Ozden I, Alper A (2006) Obstructive jaundice due to a textiloma mimicking a common bile duct stone. J Hepatobiliary Pancreat Surg. 13(2):172-3

[45]. Lin TY, Chuang CK, Wong YC, Liao HC (1999) Gossypiboma: migration of retained surgical gauze and spontaneous transurethral protrusion. BJU Int. 84(7): 879-80.

[46]. Kopka L, Fischer U, Gross A, Funke M, Oestmann J, et al., (1996) CT of retained surgical sponges (textilomas): Pitfalls in detectionand evaluation. J Comput Assist Tomogr. 20(6): 919-23. 